\title{
De la sociología del conocer a la sociología del conocimiento: la teoría de los códigos de legitimación
}

\author{
Alejandro Romero Reche ${ }^{1}$
}

Maton, Karl (2014). Knowledge and Knowers. Towards a Realist Sociology of Education. Abingdon: Routledge. ISBN: 978-0-415-47999-8, 246 pp.

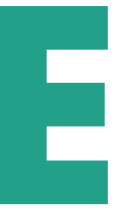

n el siglo xxi ya no tenemos tan claro que subir a hombros de gigantes vaya a ayudarnos a ver mejor.

Después de Kuhn, de Feyerabend, del «Programa Fuerte» de la sociología de la ciencia, de las teorías postmodernas y las críticas postcoloniales, de la proliferación de epistemologías del punto de vista, nos hemos quedado sin buenas razones para optar por un gigante o por otro, pues los consideramos inconmensurables: no hay unidad de medida común con que establecer quién es el más alto, ni criterio con que decidir cuál está mejor situado. Es más, habrá quien suponga que hoy en día nos interesa más derribarlos que hacer cualquier otra cosa con ellos. Dadas las circunstancias, toda defensa de una visión acumulativa del conocimiento podría considerarse una tentativa de recuperar la bisoñez inductivista del positivismo lógico y, como tal, condenada al fracaso.

En Knowledge and Knowers Karl Maton recoge y reelabora una serie de artículos publicados entre 1998 y 2012. Esta secuencia de catorce años ilustra parcialmente la evolución de la teoría de los códigos de legitimación (Legitimation Code Theory, abreviado como LCT), una propuesta para la que el carácter acumulativo del conocimiento es crucial. Y esto transpira al menos en tres niveles: en su concepción del conocimiento objetivo («objetivo» no en tanto «imparcial»o, lo que sería mucho más difícilmente sostenible, «universalmente válido», sino en el sentido del «mundo 3» popperiano, como objeto que cobra una existencia relativamente autónoma del proceso subjetivo de conocer), en su construcción a partir de los edificios teóricos de Bourdieu y Bernstein, y en el diseño abierto de su arquitectura, necesitada tanto de ulteriores desarrollos teóricos como de las investigaciones empíricas que, en definitiva, son su razón de ser.

A consecuencia de dicho diseño abierto, el libro de Maton es obligadamente parcial: no solo porque su autor no puede (ni quiere) atribuirse la representación de todas las personas que han venido trabajando en la teoría durante estos años (aunque él mismo sea una de las más relevantes), sino también porque está concebida para seguir creciendo y, por tanto, para desbordar los límites incluso de un compendio enciclopédico, algo que Knowledge and Knowers no pretende ser. Tras establecer las bases de la teoría general

1 Universidad de Granada; romeroreche@ugr.es 
en el primer capítulo, el resto del libro se dedica a explorar dos de las cinco dimensiones (especialización y semántica) del dispositivo de legitimación que establece como mecanismo generador de campos sociales de práctica.

La utilidad potencial de la teoría de los códigos de legitimación, en cuya orientación fundamentalmente práctica insiste con frecuencia Maton, no se restringe a disciplinas específicas de la sociología: «La LCT es más que Knowledge and Knowers (...). ... se podría describir más certeramente como una sociología de la legitimidad o una sociología de la posibilidad con aplicaciones más amplias». (pág. 17). La LCT es una «caja de herramientas conceptuales» y una metodología analítica para identificar los principios subyacentes a las prácticas dentro de campos sociales, que no tienen por qué ser únicamente aquellos vertebrados en torno al conocimiento.

No obstante, como introducción parcial a la LCT, Knowledge and Knowers resulta especialmente recomendable desde la perspectiva de las sociologías del conocimiento y la educación. La estructura del libro, que va encadenando estudios empíricos sucesivos mediante los cuales se profundiza en los aspectos escogidos de la teoría y se exponen algunos de sus conceptos más fecundos, es un ejemplo de construcción acumulativa de conocimientos: el lector puede apreciar cómo la perspectiva teórica se expande desde un punto de partida, la teoría de los campos sociales de Bourdieu combinada con el modelo de los códigos de Bernstein, y los efectos de cada nuevo estudio en las perspectivas que se abren para desarrollos subsiguientes y en la revisión de planteamientos anteriores. Aunque el texto peca de reiterativo en la re-exposición cíclica de ciertas nociones clave, su densidad y riqueza teórica justifican estas redundancias en tanto facilitan la asimilación de unas herramientas heurísticas que van cobrando definición a lo largo de las páginas. No se espera del lector una aceptación acrítica, ni se le ofrece un sistema acabado que deba asumir en su integridad; si Knowledge and Knowers puede leerse como un manifiesto para la captación de nuevos adeptos a la LCT es, sobre todo, por la invitación a continuar edificándola que cierra el libro en forma de capítulo final: «Construyendo una sociología realista de la educación: continuará...». Significativamente, y a diferencia de las conclusiones de cada capítulo anterior, el último epígrafe se titula «Sin conclusión» (pág. 215).

Este decidido impulso proselitista tiene como centro de operaciones una página web (www.legitimationcodetheory.com) y se despliega en numerosas iniciativas académicas y publicaciones cuya pista puede seguirse a través de aquella. Quizá la más destacable, y la que mejor podría servir de alternativa introductoria a este Knowledge and Knowers, sea el reciente volumen colectivo editado por el propio Maton, Hood \& Shay (2016), donde se ofrece una variada panorámica de aplicaciones contemporáneas de la LCT que ilustra su potencial para la construcción acumulativa de conocimiento sociológico y para el estudio de la construcción acumulativa de conocimiento en general.

A este respecto, quizá convenga incidir en una distinción que se pierde en castellano y que es fundamental para el enfoque de Maton y la LCT: la que se establece entre los verbos to build y to construct cuando su objeto es el conocimiento. Mientras constructing, a resultas de su uso en el pasado, implica cierto matiz de arbitrariedad y relativismo, característico de las visiones constructivistas del conocimiento como producto determinado por factores externos, building no se asocia necesariamente a dichas visiones. Frente al conocimiento «construido» como epifenómeno de relaciones, posiciones sociales e intereses, perfectamente intercambiable por cualesquiera otras ideas y creencias si se dieran otras circunstancias exteriores, y susceptible de demolición revolucionaria, el conocimiento «en edificación» ${ }^{2}$ es acumulativo. No por casualidad, una

2 Tal vez, siendo más fieles al espíritu que a la letra, podríamos hablar de conocimiento «edificante»... aunque no exactamente en el mismo sentido que semejante expresión tendría para Richard Rorty, quien en todo caso escribía sobre una edifying philosophy. 
de las tareas más acuciantes que según Maton deben abordar las ciencias sociales es building knowledge about knowledge-building, es decir, construir acumulativamente conocimiento sobre la construcción acumulativa de conocimiento.

Este empeño exige enmendar un error histórico de la sociología en general y de la sociología del conocimiento en particular: lo que Maton denomina «ceguera hacia el conocimiento» (knowledge-blindness). Incluso en la actualidad, en la llamada «sociedad del conocimiento», cuando tantas voces dentro y fuera de las ciencias sociales coinciden en la creciente importancia del conocimiento en los procesos de cambio social, carecemos de herramientas conceptuales para abordar el contenido, la estructura y cualesquiera otras propiedades internas de ese conocimiento que juzgamos tan decisivo. No sabemos explícitamente qué es el conocimiento; damos por supuesta una difusa concepción tácita a partir de la cual tendemos a operacionalizarlo en términos vagamente cuantitativos: en tales entornos sociales, tales actores disponen de más o menos conocimientos, como pueden disponer de más o menos dinero. En esto coinciden, por mencionar dos ejemplos que aporta Maton, tanto Castells como los mismos Bourdieu y Bernstein. Incluso cuando se establecen unidades de medida del conocimiento con objeto de ganar precisión analítica, el contenido de aquello que se mide parece hermético para las ciencias sociales. Y esto es inadmisible para una sociología de la educación digna de tal nombre. Con presumible intención polémica y burlona, el autor llega a afirmar que el conocimiento «se ha convertido en el Otro silenciado en la educación» (pág. 7).

Maton recoge la clásica crítica de Popper a la sociología del conocimiento de inspiración hegeliano-marxista, a la que imputa una notable incapacidad para comprender los aspectos sociales del conocimiento. A juicio de Popper, los que se pretenden sociólogos del conocimiento se centran en las influencias externas que condicionan el «conocer» subjetivo de cada individuo, y esto les empuja necesariamente a un relativismo que evitarían si, en efecto, considerasen el carácter social del conocimiento (especialmente del conocimiento científico), el proceso intersubjetivo que permite superar el prejuicio individual (1984 [1966]: 217). La investigación social sobre la educación manifiesta una doxa subjetivista que incurre en el mismo error: se estudian los procesos y factores que influyen en el conocer subjetivo, pero se excluye del estudio el propio conocimiento que es objeto y producto de dicho conocer.

Para pasar del relativismo autocontradictorio de la sociología del conocer a una genuina sociología del conocimiento, Maton, inspirándose en el realismo crítico, propone una salida para un falso dilema que ha malogrado el debate sobre el conocimiento. Se trata del «dilema epistemológico» que opone el absolutismo positivista al relativismo constructivista, dejando únicamente dos opciones: o bien un conocimiento universal, ahistórico y axiológicamente neutral, o bien un conocimiento socialmente construido que expresa intereses estructurales. Frente a esto, Maton recurre a tres nociones: el realismo ontológico, que sostiene que existe una realidad exterior al discurso y que ejerce cierta influencia en el conocimiento que versa sobre ella; el relativismo epistemológico, que reconoce la dependencia contextual del conocimiento; y la racionalidad de juicio, que defiende la existencia de criterios intersubjetivos para valorar distintas pretensiones de verdad. El conocimiento, por tanto, no es universal, pero responde en alguna medida a una realidad exterior y puede ser evaluado: no todo vale, aunque los parámetros para discriminar entre propuestas rivales tampoco sean universalmente válidos.

Aunque esté profundamente vinculado al proceso subjetivo de conocer, el conocimiento «objetivo» goza de autonomía relativa con respecto a aquel, lo que se pone de manifiesto en los procesos de creación (a medida que lo creado se va objetivando, influye y condiciona la labor del creador), los de 
aprendizaje (no aprehendemos la realidad de forma directa, sino a partir de conocimiento anteriormente objetivado), y en las relaciones entre conocedores dentro de campos específicos de práctica (la puesta en común de los conocimientos originados y objetivados por distintas personas produce efectos impredecibles que trascienden sus conciencias subjetivas).

Las características de ese conocimiento objetivo exterior a nuestras mentes, su naturaleza, sus propiedades y sus principios organizativos tendrán importantes consecuencias no solo en la futura construcción (o, si se quiere, edificación) de nuevos conocimientos y en su acumulación, sino también en el desarrollo de los campos sociales en los que dichos conocimientos entran en juego, y en el logro de objetivos políticos tenidos por deseables, como la inclusión social: así, por ejemplo, distintas formas de conocimiento producen distintos efectos en el aprendizaje y el éxito académico de personas procedentes de distintos entornos sociales (véase en particular el capítulo sexto, págs. 106 a 124).

En suma, no basta con observar las relaciones exteriores al conocimiento objetivo, es decir, las influencias que diversos factores sociales y psicológicos ejercen sobre él (como había venido haciendo la sociología del conocimiento y disciplinas afines); también son de vital importancia las relaciones interiores, las características internas del conocimiento.

A grandes rasgos, la LCT concibe la sociedad, a la manera de Bourdieu, como un conjunto de campos sociales superpuestos, relativamente autónomos pero interrelacionados, dentro de los cuales las personas interactúan para mejorar su posición. Sus prácticas representan, por tanto, pretensiones rivales de legitimidad que intentan redefinir las reglas del juego; y estas prácticas están condicionadas por la relación entre las disposiciones de los actores y la estructura del campo. Se expresan de acuerdo con códigos de legitimación, cada uno de los cuales representa un posible principio de organización dominante para el campo; no obstante, hay un dispositivo de legitimación subyacente que establece cuál es en efecto el código dominante y, por tanto, configura el campo social y establece quién puede hacer qué y en qué circunstancias. Parece ocioso subrayar la importancia del control de dicho dispositivo.

Maton identifica cinco códigos de legitimación, correspondientes a otras tantas dimensiones del dispositivo de legitimación, y cada uno dotado de distintas modalidades: autonomía, densidad, especialización, semántica y temporalidad. Como se ha dicho, estas dimensiones no tienen por qué agotar todas las posibles (posteriores investigaciones empíricas y desarrollos teóricos pueden dar lugar a nuevas adiciones no contempladas hasta ahora), y el libro explora únicamente dos de ellas.

Por ejemplo, las modalidades de la especialización se refieren a las relaciones de las prácticas con objetos y con sujetos: las primeras son relaciones epistémicas (si se trata de pretensiones de conocimiento, las relaciones entre éste y su objeto) y las segundas relaciones sociales (continuando con las pretensiones de conocimiento, las relaciones entre éste y el conocedor). Las relaciones epistémicas establecen qué podemos considerar legítimamente como conocimiento y las sociales, a quién podemos considerar legítimamente como conocedor.

Maton gradúa estas modalidades en dos escalas paralelas de fuerza que también recoge de Bernstein: clasificación y enmarcamiento. Simplificando analíticamente, esto da lugar a una tipología de cuatro códigos principales de especialización (págs. 30 y 31): 1) los códigos de conocimiento, donde clasificación y enmarcamiento de las relaciones epistémicas son fuertes, mientras que en el caso de las sociales son débiles: cuando rige este principio, las características del conocedor son irrelevantes, pues lo fundamental es la posesión de un conocimiento especializado sobre un objeto de estudio muy definido; 2) los 
códigos de conocedor (clasificación y enmarcamiento de las relaciones epistémicas débiles, relaciones sociales fuertes), donde lo principal son determinados atributos específicos del conocedor; 3) los códigos de élite (relaciones epistémicas y sociales fuertes), donde cuentan tanto el conocimiento especializado como los atributos del conocedor; y 4) los códigos relativistas (relaciones epistémicas y sociales débiles), en los que toda pretensión de conocimiento goza de la misma legitimidad.

Esta primera aproximación a los códigos de especialización permite a Maton analizar el desarrollo histórico de los Cultural Studies británicos y detectar, en las características internas del conocimiento generado y difundido por estos, una de las principales causas de su fragilidad institucional y de la clausura en 2002 del Centre for Contemporary Cultural Studies de la Universidad de Birmingham (Maton señala que en el artículo originalmente publicado en 2000 él ya expresaba serias dudas sobre la continuidad de la institución). Al tratarse de un conocimiento organizado de acuerdo con códigos del conocedor, se produce lo que Maton denomina una «procesión de los excluidos», que reivindican sucesivamente la especificidad irreducible del conocimiento asociado a posiciones concretas, marginadas hasta ese momento, y una fragmentación del campo e incluso una conflictividad de legitimidades inconmensurables que dificulta la acción conjunta. A juicio del autor, la sociología de la educación padece de una dolencia similar, vertebrada igualmente por códigos del conocedor, y se beneficiaría de un fortalecimiento de las relaciones epistémicas.

Knowledge and Knowers ofrece argumentos muy persuasivos para contemplar la posibilidad de que la LCT sea precisamente lo que necesita la sociología de la educación para superar algunos achaques que parecen endémicos. A diferencia de la inmensa mayoría de aproximaciones anteriores a la sociología del conocimiento, quienes la vienen edificando se han cuidado de revisar los cimientos para no dejar en ellos, por descuido, alguna trampa relativista autodestructiva: la LCT se puede aplicar al estudio de la LCT sin que, como ocurre cuando (por ejemplo) se aplica el «Programa Fuerte» de la Sociología de la Ciencia al "Programa Fuerte" de la Sociología de la Ciencia, se caiga en una paradoja sin solución.

Aun así, quedan muchas plantas, alas y habitaciones que añadir al edificio y, dada la naturaleza impredecible del conocimiento, no podemos saber aún qué encontraremos, qué construiremos en ellas, y qué consecuencias tendrá esto para el conjunto de la estructura. Haciendo alarde de creatividad teórica, inventiva terminológica y rigor argumentativo en su exposición de las pretensiones de legitimidad de la teoría de los códigos de legitimación, Maton consigue convencer al lector de que, como mínimo, vale la pena averiguarlo.

\section{Referencias bibliográficas}

Maton, Karl; Hood, Susan \& Shay, Suellen (eds.) (2016). Knowledge-Building: Educational Studies in Legitimation Code Theory. Abingdon: Routledge.

Popper, Karl R. (1984 [1966]): The Open Society and Its Enemies. Volume II. The High Tide of Prophecy: Hegel, Marx and the Aftermath. Londres: Routledge. 